\title{
Technology Acceptance of a Gold Dinar Based Electronic Payment System
}

\author{
Mohd-Nazri Muhayiddin ${ }^{1 *}$, Elsadig Musa Ahmed ${ }^{2}$, Hishamuddin Ismail $^{3}$ \\ ${ }^{1}$ Faculty of Entrepreneurship \& Business, Universiti Malaysia Kelantan, Kota Bharu, Malaysia; ${ }^{2}$ Faculty of Business \& Law, Multi- \\ media University, Melaka, Malaysia; ${ }^{3}$ Faculty of Business \& Law, Multimedia University, Melaka, Malaysia. \\ Email: *mnazri@umk.edu.my, \{elsadig.musa, hisham\}@mmu.edu.my
}

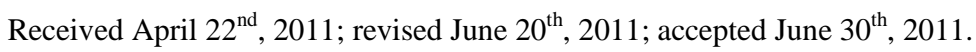

\begin{abstract}
This study is intended to solve a few constraints existed in physical gold dinar when used as a form of payment. One dinar is equal to 4.25 gram of fine gold. Specifically, this work proposes the use of e-commerce technology to solve those constraints. But before the actual system can be implemented, this research seeks to find out whether or not the public would be ready to adopt the concept of an electronic dinar payment system. The research framework is based on Unified Theory of Acceptance and Use of Technology (UTAUT) [1]. It measures the user acceptance based on these constructs; performance expectancy, effort expectancy, social influence, facilitating conditions, behavioral intention to use. In addition, anxiety and perceived credibility are added as two new constructs. Data collection is based on a questionnaire survey. From the descriptive analysis results, it is discovered that most of the respondents participated in this survey generally agree with the idea of using the proposed dinar based payment system (mean rating of above 4.00).
\end{abstract}

Keywords: Electronic Payment Systems, Inflation, Monetary Economics, Gold Dinar

\section{Introduction}

With the prices of gold and silver having hit a new "all-time" high in August 2011, our society has begun to take notice and thus started to ponder on the importance of the two precious metals (gold and silver). It was reported [2] that the US dollar has lost $82 \%$ of its purchasing power, as measured by the Consumer Price Index (CPI) since 1971. The author [2] further illustrated that if 100 widgets can be bought with $\$ 1$ in 1971, only 18 of such widgets can be bought for $\$ 1$ in 2006. Mathematics calculation will reveal something even more startling. Back then in 1971 the price of gold was \$35 per ounce [3]. At its highest price (11 August 2011), we need to fork out $\$ 1786$ [4] to buy exactly the same one ounce of gold. Thus from 1971 to 2011 (in 40 years), in terms of US dollars, the inflation has gone up by $5003 \%$ i.e. (1786- 35)/35 $\times 100 \%$. Or equivalently, for the duration of 40 years, the US dollar has lost $5003 \%$ of its purchasing power. The strength of purchasing power in gold and silver has become known facts by now and it is widely discussed in many literatures [3,5,6].

\section{Background of Problem}

In order to be as close to a practical situation as possible, this study uses actual data (from real Malaysian market) to show the superior performance of gold's purchasing power as compared to that of Ringgit Malaysia (RM). Prices of a few inflationary items are shown in RM as well as their corresponding prices in dinar (gold). In this case, the price performance (purchasing power) between these two competing currencies can be compared side by side. The readers can therefore make a straight-forward comparison on the performance of purchasing power between fiat currency and that of sound money (dinar and dirham).

Tables 1 to 4 below illustrate the performance of dinar as compared to the performance of fiat currency (i.e. RM) for various critical consumer items and services. It is to be noted that dinar is to be used for high-valued items whereas dirham is used for low-valued items. Table $\mathbf{5}$ shows salary comparison-paid in dinar versus paid in Ringgit Malaysia (RM).

It is to be noted that oil and electricity prices are two inflationary items whereby any price increase in these two items will subsequently give rise to prices of other daily food items [2,7]. Similarly, construction items will give subsequent price rise to construction-related markets such as commercial (office) and residential (house) build- 
Table 1. Fuel price comparison (in RM and Dinar).

\begin{tabular}{ccc}
\hline Petrol (50 liter) & RM & Dinar \\
\hline 2000 & 60.00 & 0.428 \\
2009 & 90.00 & 0.178 \\
Price increase/decrease & $\mathbf{+ 5 0 \%}$ & $\mathbf{- 5 8 \%}$ \\
\hline & & \\
\hline Diesel (50 liter) & $\mathbf{R M}$ & Dinar \\
\hline 2000 & 35.50 & 0.253 \\
2009 & 85.00 & 0.168 \\
Price increase/decrease & $\mathbf{+ 1 3 9 \%}$ & $\mathbf{- 3 4 \%}$ \\
\hline
\end{tabular}

Note: Prices of gold are USD270 and USD1050 respectively per ounce in Oct. 2000 and Oct. 2009 (London fix); Prices of petrol are RM1.20 and RM1.80 respectively per liter in 2000 and 2009; Prices of diesel are RM0.71 and RM1.70 respectively per liter in 2000 and 2009.

Table 2. Electricity price comparison (RM and Dinar).

\begin{tabular}{|c|c|c|}
\hline Electricity (Domestic, 300 kWh) & $\mathbf{R M}$ & Dinar \\
\hline 2000 & 69.40 & 0.495 \\
\hline 2009 & 72.50 & 0.233 \\
\hline Price increase/decrease & $+4 \%$ & $-53 \%$ \\
\hline Electricity (Commercial, 3000 kWh) & $\mathbf{R M}$ & Dinar \\
\hline 2000 & 864.00 & 6.163 \\
\hline 2009 & 969.00 & 3.114 \\
\hline Price increase/decrease & $+12 \%$ & $-49 \%$ \\
\hline
\end{tabular}

Note: Prices of gold are USD270 and USD1050 respectively per ounce in Oct. 2000 and Oct. 2009 (London fix).

Table 3. Construction items price comparison (RM and Dinar).

\begin{tabular}{ccc}
\hline Cement (100 kg) & RM & Dinar \\
\hline 2005 & 25.00 & 0.115 \\
2007 & 29.00 & 0.090 \\
Price increase/decrease & $+\mathbf{1 6 \%}$ & $\mathbf{- 2 1 \%}$ \\
\hline & & \\
\hline Steel (1 ton) & $\mathbf{R M}$ & $\mathbf{D i n a r}$ \\
\hline 2005 & 1800.00 & 8.254 \\
Price increase/decrease & 2100.00 & 6.551 \\
\hline
\end{tabular}

Note: Prices of gold are USD420 and USD690 respectively per ounce in 2005 and 2007 (London fix).
Table 4. Cost of Hajj (travel) in RM and Dinar.

\begin{tabular}{ccc}
\hline Cost of Hajj (lowest package) & RM & Dinar \\
\hline 2002 & 13,500 & 93.53 \\
2009 & 19,990 & 39.53 \\
Price increase/decrease & $\mathbf{+ 4 8 . 1 \%}$ & $\mathbf{- 5 7 . 7 \%}$ \\
\hline
\end{tabular}

Note: Prices of gold are USD278 and USD1050 respectively per ounce in 2002 and 2009 (London fix). Cost of Hajj is based on the lowest THTS package as per stated in TH Annual Report; (TH: Tabung Haji, THTS: TH Travel \& Services)

Table 5. Salary comparison in RM and Dinar.

\begin{tabular}{ccc}
\hline Salary Paid (Malaysia) & Dinar & RM \\
\hline Jan 1992 & $\mathbf{1 5 . 5 0}$ & $* \mathbf{1 8 0 0}$ \\
Jan 2007 & 15.50 & 4968 \\
Feb 2009 & 15.50 & 6975 \\
Oct 2009 & 15.50 & 7838 \\
\hline
\end{tabular}

Note: Price of gold in Jan. 1992 is USD340 per ounce. Price of gold in Jan. 2007 is USD690 per ounce; Price of gold in Feb. 2009 is USD915 per ounce; Price of gold in Oct. 2009 is USD1050 per ounce; *RM1800 is a starting salary for a fresh engineer in Malaysia in 1992; (All gold prices are based on London fix price).

ings. As for the case of salary, Table 5 clearly shows that dinar preserve the value of salaries over time. Apparently, salaries paid in dinar appreciate over time automatically, even without annual increments.

It should be noticed from the tables above that the performance of dinar is much superior as compared to that of RM (or other fiat money). Apparently in all tables, what appears to be a "price increase (inflation)" in RM is merely a "price decrease" in dinar. It becomes obvious from the above tables that dinar (gold) is able to preserve their "intrinsic value"; whereas the paper (fiat) money simply could not do that.

Although gold (dinar) offers very good purchasing power, however there exist a few physical constraints with the precious metal. The first of such constraints is it is physically heavier and thus difficult to be carried around for normal daily transactions. Secondly, due to its softness (malleability), the physical dinar would be subjected to continuing "wear and tear" process if it were to be used repeatedly among the masses; be it to be done intentionally or otherwise. It was reported in [8] that during the civilization of the Roman Empire, their ordinary citizens would clip the precious metal from the empire's coins perimeter in order to steal some of the value stored in the coins. The author [8] further wrote that slaves during that time "sweated" the coins by jiggling them in woolen bags hour after hour in order to wear-off some of the gold. The third constraint that needs to be 
addressed would be how to identify the purity of dinar denominations in each transaction such that fraud and cheating cases would be minimized and if possible, totally prevented. The fourth is divisibility constraint associated with the dinar. In today's price, the value of 1 dinar is in the range of RM800-RM850 a piece, thus making it impractical for buying of small-priced items. The last constraint of physical dinar is the possible consumer losses due to the existence of buying and selling prices (known as spread) imposed by dinar traders. Shop owners will accept the value of physical dinar at buying prices (lower) instead of at selling prices (higher).

Therefore those issues of portability, wear and tear, purity concern, divisibility and the dinar spread-all of them must be properly addressed in order for dinar to be widely accepted by the public. In particular, this work would focus on using the e-commerce technology in a form of an electronic payment system to solve a few limitations associated with dinar (gold). The reason to introduce the electronic commerce technology in dinar is because it offers several advantages that the physical (brick-and-mortar) methods of dinar transactions simply could not offer. This research believes that the electronic commerce technology is capable of solving such a few constraints associated with the physical dinar. With the use of electronic dinar payment system, the physical movements of dinar will be expected to be very minimal, and thus it is believed it can solve the portability issue. Apart from that, the electronic dinar payment system would also solve problem with "wear and tear" since users do not keep their dinar at their premises but rather in storage vaults somewhere else with user accounts strictly associated with each of them. Another advantage offered by electronic dinar payment system is the ability to bypass unnecessary checking of purity; due to the fact that the dinar is kept at providers' storage vaults whereby its purity are already known beforehand and they are undisturbed by outside parties. As for divisibility constraint; electronic dinar payment system would enable customers to buy small-valued items e.g. up to 0.001 dinar (equivalent to RM0.80) because data are stored and processed by computers. Furthermore, using electronic dinar payment system would be much safer, because we don't carry the expensive gold in our pocket-only its electronic representation. Lastly, the proposed electronic dinar payment system would also be able to solve problems with 'spread' imposed by gold sellers. If this electronic dinar payment system could be set-up as identical as possible to credit/debit card system, the 3\% - 5\% spread value would be converted into a transaction fee. This kind of fee would normally be absorbed by the shop owners. Therefore all in all, the proposed electronic dinar payment system would solve a few constraints with physical dinar, and at the same time it carries with it the great advantage of purchasing power.

But before the actual system can be implemented in Malaysian market, this research attempts to find out beforehand whether the public would be willing to adopt the proposed dinar electronic payment system. Specifically, this research would explore what are those factors that influence the acceptance of the electronic dinar payment system. Those factors could be a positive factor whereby it will enhance the effect of intention to use; or it could as well be a negative factor of which in this case it will degrade the effect of intention to use. Following a research framework adapted from Unified Theory of Acceptance and Use of Technology (UTAUT), those factors would include performance expectancy, effort expectancy, social influence, facilitating conditions, perceived credibility, and anxiety.

\section{Literature Review}

An understanding of technology acceptance models is very important in order to fully appreciate why one model is chosen over the other. Researchers are always confronted with choosing the most appropriate model for their particular researches. Often times, they must "pick and choose" constructs among the various models available. Alternatively, they may choose one "favored model" and largely ignore the possible contributions from other models. Effort by [1] to solve this predicament is greatly welcomed among the information system (IS) research circles. His [1] team has introduced and tested the new and unified model, known as Unified Theory of Acceptance and Use of Technology (UTAUT) which integrates the previous eight (8) models used in technology acceptance studies. Those eight models are: Theory of Reasoned Action (TRA), Technology Acceptance Model (TAM), Motivational Model (MM), Theory of Planned Behavior (TPB), a model which combines TAM and TPB (C-TAM-TPB), Model of PC Utilization (MPCU), Innovation Diffusion Theory (IDT), and Social Cognitive Theory (SCT).

With the objective of introducing a comprehensive model that considers all variables included in the previous eight prominent models, [1] developed a research to empirically compare and test each of the constructs in those models. Their research has found that the eight previous models were able to explain (between) 17 percent to 53 percent of the variance in user intentions (that is, to use information technology). Subsequently, a unified model (UTAUT) that integrates elements across the eight models are thereby formulated and empirically validated. With UTAUT, it is found the model had outperformed the previous eight individual models (adjusted $R^{2}$ of 69 percent). Later, UTAUT was validated with data 
from two new organizations; it still gave very similar results (adjusted $R^{2}$ of 70 percent). Having had this substantial improvement over its predecessors, UTAUT would thus provide a very useful tool in order to assess the likelihood acceptance factors of introducing a new technology.

Therefore, the research framework for this work is adapted from UTAUT with two additional variables added. This study intends to find out the consumer acceptance of electronic dinar payment system based on the four original constructs of UTAUT model. Those constructs are performance expectancy, effort expectancy, social influence, and facilitating conditions. This research also intends to find out how significant is the contributions of moderators in this case. Out of four moderators in the original UTAUT model, only three would be applied in this study. Those three moderators are gender, age, and experience while the fourth moderator (voluntariness of use) is not included since the proposed electronic dinar payment system would be purely voluntary in nature and therefore its purpose is irrelevant in this case. The two additional variables, "perceived credibility" and "anxiety", are hypothesized to be very relevant to this study and therefore their influence is expected to be significant in the proposed model. Anxiety is adapted from [9] as well as [1] while perceived credibility is adapted from [10]. Table 6 explains all constructs included in this research framework. Figure 1 illustrates the model of research framework used for this study.

\section{Methodology}

This research is a quantitative research whereby an analysis and classification of numerical data will be collected from survey questionnaires. The questionnaires will be developed based on research frameworks which is adapted from the Unified Theory of Acceptance and Use of Technology (UTAUT) model-with two extra variables added (anxiety, and perceived credibility). The introduction of two variables is specifically tailored to reflect the individual technology acceptance of electronic dinar payment system. All surveys consist of a closedended question. Respondents will only choose answers already provided with the questions.

This paper investigates the descriptive analysis results, of which the survey was distributed to 500 respondents in the Multimedia Super Corridor (MSC) area in Malaysia.

Table 6. Research framework core constructs used in this study.

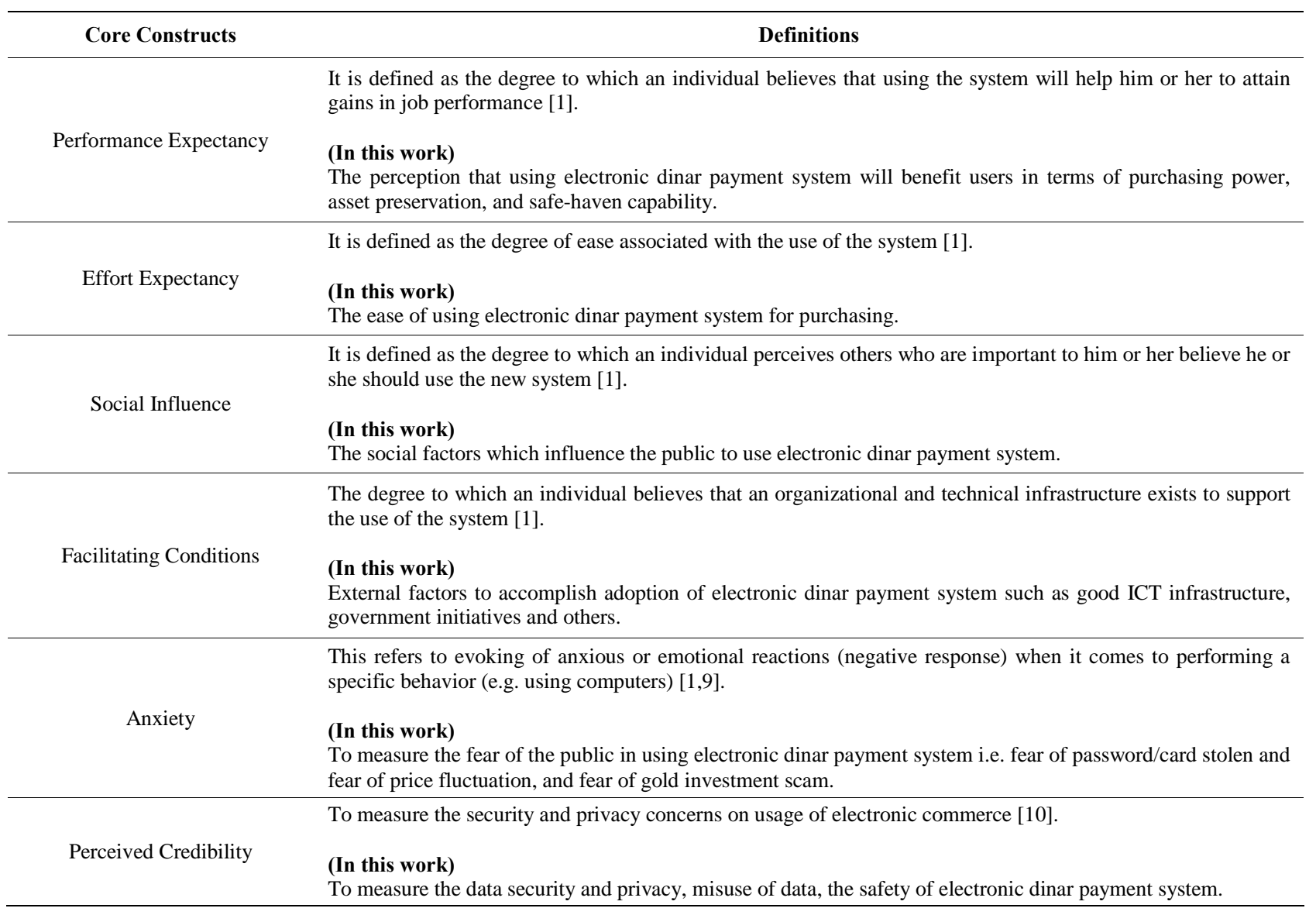




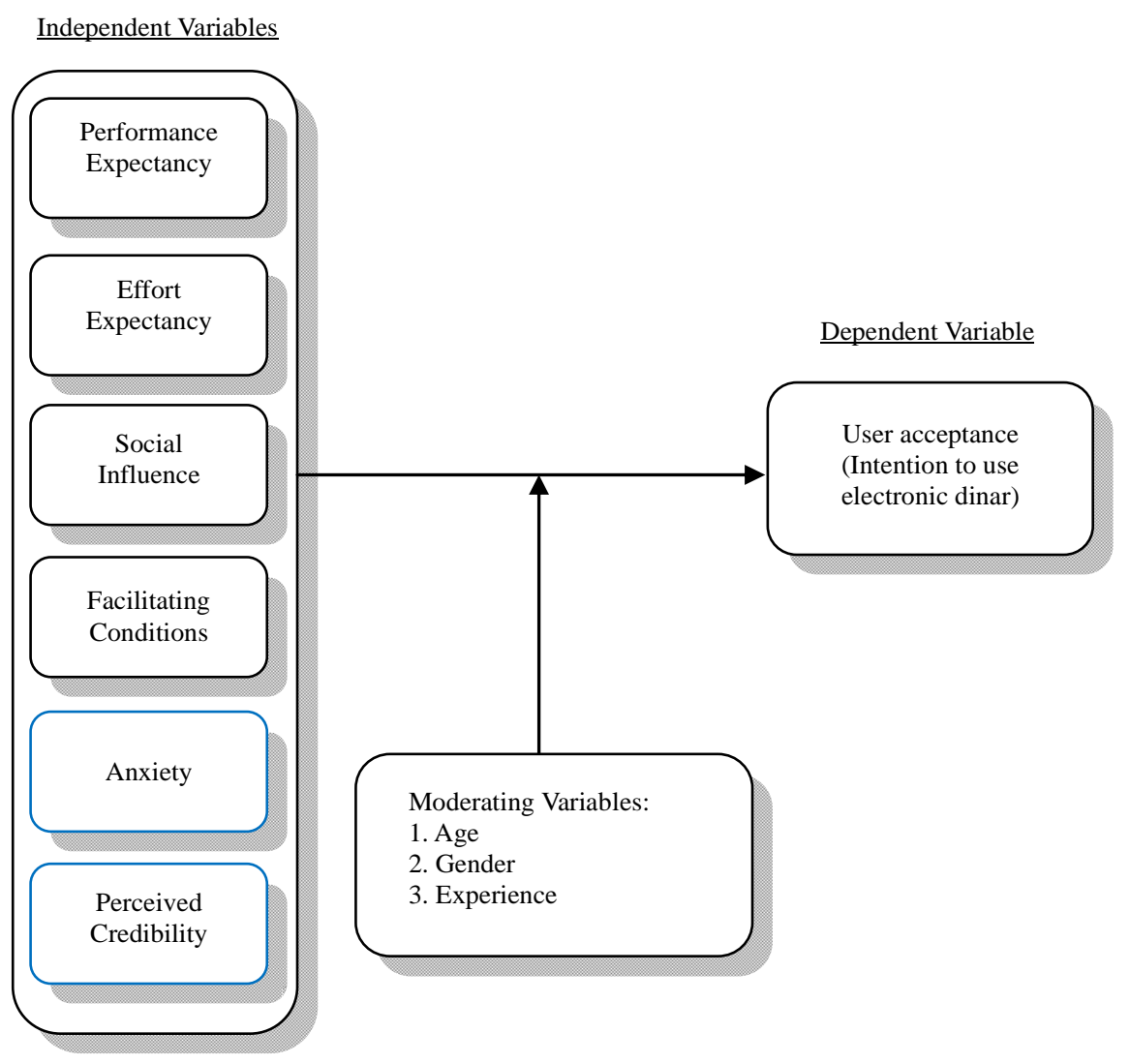

Figure 1. Research framework for user acceptance of electronic dinar payment system.

The MSC area is selected because e-commerce applications are widely expected to be active in those areas. The response rate was $87.2 \%$ (436 respondents had answered it completely). The first section of the survey contains questions related to respondents' experiences with e-commerce, gold, and dinar. Section A contains questions related to performance expectancy. Section B has questions measuring effort expectancy. Section $C$ has questions related to social influence. Section D consists of questions investigating factors related to facilitating conditions. Section E investigates factors related to anxiety (concerns) of adopting the proposed electronic dinar payment system. Section F measures perceived credibility (security and privacy concerns). Section G contains at least three questions measuring respondents' behavioural intention to use the electronic dinar payment system. The last section of the survey consists of questions related to respondents' information such as gender, race, age, monthly income, educational attainment, marital status, and employment status. A five-point Likert scale is used to measure to what extent an individual agree or disagree to the questions being asked. Likert scale is measured as follows: " 1 " is for Strongly Disagree, "2" is for Dis- agree, "3" is for neither agree nor disagree, " 4 " is for Agree, and " 5 " is for Strongly Agree. The SPSS software is used in this descriptive analysis of the collected data.

\section{Results}

Table 7 shows the general profiles of the respondents participated in this study.

Table 7. Profiles of the respondents.

\begin{tabular}{cccc}
\hline & & Frequency & Percent \\
\hline Gender & Male & 263 & 60.3 \\
& Female & 173 & 39.7 \\
& Below 24 & 28 & 6.4 \\
& $25-39$ & 334 & 76.6 \\
& 40 and above & 74 & 17.0 \\
& Yes & 239 & 54.8 \\
Experience (buying dinar) & No & 197 & 45.2 \\
\hline
\end{tabular}




\section{Discussion}

Overall, most of the respondents in this study would agree on the idea of using electronic dinar payment system. This is based on their ratings of behavioral intention to use which range from 3.98 to 4.03 (mean rating of 4.01). This is a positive result and in agreement with the ratings of independent variables that are supposed to influence it. The ratings of those independent variables will be discussed next.

\subsection{Performance Expectancy}

It can be concluded that the respondents agree with the performance expectancy construct (Table 8) with its ratings range from 4.00 to 4.14 . The first four items with ratings greater than 4.00 show that most respondents agree with the advantage of electronic dinar in terms of appreciating values, purchasing power, inflation proof and "safe haven" capability. The last two factors in this construct carry slightly lower influence with ratings of only 4.00 for both of them. The two factors show that a few respondents are still not sure whether or not the sys-

Table 8. Ratings of BI and factors affecting respondents' intention to use.

\begin{tabular}{|c|c|c|c|}
\hline \multicolumn{2}{|l|}{ Performance Expectancy } & Mean & SD \\
\hline \multicolumn{2}{|l|}{ PE1: gold's appreciation } & 4.10 & 0.590 \\
\hline \multicolumn{2}{|l|}{ PE2: gold's purchasing power } & 4.06 & 0.594 \\
\hline \multicolumn{2}{|l|}{ PE3: protection against inflation } & 4.14 & 0.627 \\
\hline \multicolumn{2}{|l|}{ PE4: protection during currency crisis } & 4.12 & 0.633 \\
\hline \multicolumn{2}{|l|}{ PE5: accomplish payment quicker } & 4.00 & 0.678 \\
\hline \multicolumn{2}{|l|}{ PE6: payment efficiency } & 4.00 & 0.708 \\
\hline Effort Expectancy & \multicolumn{2}{|l|}{ Mean } & SD \\
\hline EE1: easy to use & \multicolumn{2}{|l|}{4.02} & 0.509 \\
\hline EE2: easy to learn & \multicolumn{2}{|l|}{3.98} & 0.529 \\
\hline EE3: easy to interact & \multicolumn{2}{|l|}{3.97} & 0.558 \\
\hline EE4: compatibility & \multicolumn{2}{|l|}{3.97} & 0.580 \\
\hline EE5: convenience & \multicolumn{2}{|l|}{4.21} & 0.592 \\
\hline \multicolumn{2}{|l|}{ Facilitating Condition } & Mean & SD \\
\hline \multicolumn{2}{|l|}{ FC1: safe (to carry) } & 4.23 & 0.586 \\
\hline \multicolumn{2}{|l|}{ FC2: safety (banks keep it) } & 4.22 & 0.583 \\
\hline \multicolumn{2}{|l|}{ FC3: ‘wear and tear’ issue } & 4.24 & 0.567 \\
\hline \multicolumn{2}{|l|}{ FC4: protected from rubbing, clipping } & 4.23 & 0.611 \\
\hline \multicolumn{2}{|l|}{ FC5: purity issue } & 4.18 & 0.722 \\
\hline \multicolumn{2}{|l|}{ FC6: divisibility issue } & 4.14 & 0.754 \\
\hline
\end{tabular}

\begin{tabular}{|c|c|c|c|}
\hline \multicolumn{2}{|l|}{ Social Influence } & Mean & SD \\
\hline \multicolumn{2}{|l|}{ SI1: people who influence } & 3.90 & 0.542 \\
\hline \multicolumn{2}{|l|}{ SI2: people who are important } & 3.90 & 0.584 \\
\hline \multicolumn{2}{|l|}{ SI3: family factor } & 3.86 & 0.618 \\
\hline \multicolumn{2}{|l|}{ SI4: friends factor } & 3.85 & 0.620 \\
\hline \multicolumn{2}{|c|}{ SI5: people who understand gold's value } & 4.16 & 0.641 \\
\hline \multicolumn{2}{|c|}{ Perceived Credibility } & Mean & SD \\
\hline \multicolumn{2}{|l|}{ PCR1: personal information } & 4.17 & 0.743 \\
\hline \multicolumn{2}{|l|}{ PCR2: secured transactions } & 4.19 & 0.661 \\
\hline \multicolumn{2}{|c|}{ PCR3: companies should be trustworthy } & 4.51 & 0.641 \\
\hline \multicolumn{2}{|c|}{ PCR4: services own by owned by government } & 4.20 & 0.898 \\
\hline \multicolumn{2}{|c|}{ PCR5: services operated by major banks } & 4.35 & 0.707 \\
\hline \multicolumn{2}{|c|}{ PCR6: backed by physical dinar coins } & 4.47 & 0.589 \\
\hline \multicolumn{2}{|c|}{ PCR7: physical dinar coins withdrawal allowed } & 4.47 & 0.573 \\
\hline \multicolumn{2}{|l|}{ PCR7: widely accepted } & 4.52 & 0.561 \\
\hline Anxiety & & Mean & SD \\
\hline \multicolumn{2}{|l|}{ ANX1: gold investment scam } & 4.26 & 0.873 \\
\hline \multicolumn{2}{|l|}{ ANX2: computer hacking } & 4.27 & 0.768 \\
\hline \multicolumn{2}{|l|}{ ANX3: gold price fluctuation } & 3.86 & 1.027 \\
\hline ANX4: losing card or passn & & 3.48 & 1.137 \\
\hline ANX5: lack of internet and & ter skills & 1.91 & 1.245 \\
\hline Behavioral Intention (BI) & Mean & S & \\
\hline BI1: intend to use & 4.02 & 0.5 & \\
\hline BI2: predict to use & 3.98 & 0.5 & \\
\hline BI3: plan to use & 4.03 & 0.5 & \\
\hline
\end{tabular}

tem would be effective. This skepticism is understood since the actual electronic dinar payment system is not there yet in the market and therefore they have no experience of using the system.

\subsection{Effort Expectancy}

Most of the respondents agree that electronic dinar payment system would be easy to use, learn, and interact if is similar to existing electronic payment systems (ratings of 3.97 to 4.02 ). The 4.21 rating on the last factor in this construct (convenience) shows that they would agree using electronic dinar would be more convenient compared to using physical dinar coins.

\subsection{Facilitating Condition}

This construct has scores of $>4.00$ in all of their factors 
(six of them). The range is from 4.14 to 4.24 . Those factors that can facilitate the effective usage of electronic dinar payment system are explored in this construct. So it is not surprising, this construct carries high ratings. Please refer to Table 8 for factors influencing this construct.

\subsection{Social Influence}

There appears to be a mixed perception from respondents whether factors from this construct could influence their acceptance of electronic dinar payment system. Among the first four factors, the "people who influence" and "people who are important" factors carry the highest rating (3.90). Family and friends items carry slightly lower influence (ratings 3.86 to 3.85 respectively). However, most of them agree with the perception that those who understand the true value of gold would likely use this system (rating 4.16).

\subsection{Perceived Credibility}

This is another construct which has scores $>4.00$ in all of their factors (ratings from 4.17 to 4.52 ). Most of the respondents agree that perceived credibility is an important construct that will determine whether or not they intend to accept the proposed electronic dinar payment system in the future.

\subsection{Anxiety}

Most of the respondents are sure that they would be afraid to use the proposed electronic dinar system due to the many cases of gold investment scam and also due to problems with hacking in computer/payment systems (ratings of 4.26 and 4.27 respectively). For factors 3 and 4 i.e. afraid of gold price going down and afraid of losing card or password, respondents are pretty much undecided in their opinions (mean 3.86/SD = 1.027 and mean 3.48/ $\mathrm{SD}=1.137$ respectively). However, most of them disagree with factor 5 i.e. they are not afraid of lacking internet and computer skills (rating 1.91). The standard deviation of 1.245 in factor 5 indicates that respondents are quite dispersed in opinion with regards to this factor.

\section{Conclusions and Limitations}

This research added a new research framework to an acceptance study of a dinar system in Malaysia, particularly in the study of the electronic version of dinar payment system. The framework for this research is adapted from UTAUT model with an addition of two new constructs; to suitably explore the "intention to use" of an electronic dinar payment system. This study discovered that most of the respondents generally agree to accept the idea of using the proposed electronic dinar payment system. Ap- parently, it is found that certain factors are perceived to have stronger influence than the others. This is generally expected in any information system (IS) acceptance studies whereby different factors do exert various degree of influence on different constructs. The performance expectancy, facilitating condition, and perceived credibility carry the most weight (4.00 and above) among all of the constructs. It is expected that researchers and practitioners in dinar and dirham institutions would benefit from this study. This result has given an early indication as to what would be the public's acceptance of dinar and dirham in the near future. This research is limited in its generalization due to the fact that the data were taken only in the Multimedia Super Corridor area. The results would have been more significant if the survey data is covered for the whole Malaysia. Furthermore, due to the constraints on the length of the paper, the multiple regression analysis and the effects of moderating variables (such as age, gender, and experience) have not been examined in this descriptive study. These two limitations will be taken up later in our future publications.

\section{REFERENCES}

[1] V. Venkatesh, M. G. Morris, G. B. Davis and F. D. Davis, "User Acceptance of Information Technology: Toward a Unified View,” MIS Quarterly, Vol. 27, No. 3, 2003, pp. 425-478.

[2] N. Barisheff, “August 15, 1971: Inflation Unleashed," 2006. http://www.bmgbullion.com/document/316

[3] N. Lewis, "Gold, the Once and Future Money," John Wiley \& Sons, New Jersey, 2007.

[4] Kitco Inc., "Past Historical London Fix,” 2011. http://www.kitco.com/gold.londonfix.html

[5] A. K. M. Meera, “The Islamic Gold Dinar,” Pelanduk Publication, Selangor, 2002.

[6] J. Turk and J. Rubino, "The Coming Collapse of the Dollar and How to Profit from It,” Currency Doubleday (Division of Random House Inc.), New York, 2004.

[7] S. Leeb and G. C. Strathy, "The Coming Economic Collapse: How You Can Thrive When Oil Costs \$200 a Barrel,” Warner Business Books, New York, 2006.

[8] D. Paarlberg, "An Analysis and History of Inflation,” Praeger Publishers, Connecticut, 1993.

[9] D. R. Compeau and C. A. Higgins, "Computer Self-Eficacy: Development of a Measure and Initial Test," MIS Quaterly, Vol. 19, No. 2, 1995, pp. 189-211.

[10] Y. S. Wang, Y. M. Wang, H. H. Lin and T. I. Tang, “Determinants of User Acceptance of Internet Banking: An Empirical Study," International Journal of Service Industry Management, Vol. 14, No. 5, 2003, pp. 501-519. doi:10.1108/09564230310500192 